\title{
Multiplicação in vitro de copo-de-leite: espectros de luz e sacarose
}

\author{
Calla lily in vitro multiplication: spectrum of light and sucrose
}

\author{
Márcia de Nazaré Oliveira Ribeiro ${ }^{\mathrm{I}}$ Moacir Pasqual' ${ }^{\mathrm{II}}$ Adriano Bortolotti da Silva ${ }^{\mathrm{II}}$ \\ Vantuil Antônio Rodrigues ${ }^{\mathrm{II}}$
}

\section{RESUMO}

O espectro luminoso pode alterar a morfogênese das plantas por meio de uma série de processos mediados por receptores de luz, principalmente na região do vermelho $e$ azul. O objetivo deste trabalho foi determinar um possível tipo de luz mais ativo que a luz branca, de forma a aumentar a eficiência da multiplicação in vitro de copo-de-leite e obter um nível ótimo de sacarose. Para isso, os tratamentos consistiram em quatro diferentes tipos de luz, sob os quais os explantes cresceram (branca, vermelha, azul e verde), fornecidos pelo espectro luminoso das lâmpadas fluorescentes coloridas T8 20W Ecolume 05/1 e sacarose (0; 15; 30; 45 e $\left.60 \mathrm{~g} \mathrm{~L}^{-1}\right)$. O meio de cultura constituiu-se dos sais e das vitaminas de $\mathrm{MS}$, adicionado de $5 \mathrm{mg} \mathrm{L}^{-1}$ de BAP e 5,5g $\mathrm{L}^{-1}$ de ágar. $O$ tipo de luz não influencia a multiplicação in vitro de copo-de-leite, e o maior número de brotos $(2,0)$ é obtido em $45 \mathrm{~g} \mathrm{~L}^{-1}$ de sacarose. Observou-se maior número de folhas em luz branca $(3,8)$ e azul $(2,9)$, com 15 e $60 \mathrm{~g} L^{-1}$ de sacarose, respectivamente. Maior comprimento dos brotos $(3,7 \mathrm{~cm})$ foi observado em $60 \mathrm{~g} \mathrm{~L}^{-1}$ de sacarose, e maior fitomassa fresca da parte aérea $(1,07 \mathrm{~g})$ foi observada com a utilização de $60 \mathrm{~g} \mathrm{~L}^{-1}$ de sacarose.

Palavras-chave: cultura de tecidos, tipos de luz, sacarose, Zantedeschia aethiopica.

\section{ABSTRACT}

Light spectrum can modify plant morphogenesis through a number of processes mediated by light receptors, mainly in the red and blue region. The aim of this work was to determine a possible light type more active than the white light, and an optimized sucrose concentration, in order to increase the efficiency of the calla lily in vitro multiplication. To that end, the treatments consisted of four different light types (white, red, blue and green), under which the explants grew, supplied by colored T8 20W Ecolume 05/1 fluorescent lamps and various sucrose concentrations $\left(0 ; 15 ; 30 ; 45\right.$ and $\left.60 \mathrm{~g} \mathrm{~L}^{-1}\right)$. The culture medium contained $M S$ salts and vitamins, added of $5 \mathrm{mg} \mathrm{L}^{-1}$ BAP and $5.5 \mathrm{~g} \mathrm{~L}^{-1}$ agar. The light type did not influence in vitro propagation of calla lily and there were a higher number of sprouts (2.0) in $45 \mathrm{~g} \mathrm{~L}^{-1}$ of sucrose. There was higher number of leaves in white (3.8) and in blue light (2.9) with 15 and $60 \mathrm{~g} \mathrm{~L}^{-1}$ of sucrose, respectively. Higher length of sprouts $(3.7 \mathrm{~cm})$ was observed in $60 \mathrm{~g} \mathrm{~L}^{-1}$ of sucrose and higher fresh weight of the aerial part $(1.07 \mathrm{~g})$ in $60 \mathrm{~g} \mathrm{~L}^{-1}$ of sucrose.

Key words: tissue culture, light type, sucrose, Zantedeschia aethiopica.

\section{INTRODUÇÃO}

Existem vários fatores determinantes do crescimento e do desenvolvimento na maioria dos sistemas de cultivo in vitro. Dentre eles, estão as condições de luz às quais as culturas estão expostas. Os processos fotossintéticos e fotomorfogenéticos são influenciados pela luz incidente, principalmente em relação à qualidade (comprimento de onda), quantidade (fluxo de fótons) e duração (fotoperíodo). Os componentes comprimento de onda e densidade de fluxo luminoso podem ter efeitos positivos e ou negativos no cultivo in vitro (KODYM \& ZAPATAARIAS, 1998).

A luz é um fator fundamental para as plantas pela ação direta ou indireta na regulação de seu crescimento e desenvolvimento (MORINI \& MULEO,

IPrograma de Pós-graduação em Agronomia/Fitotecnia, Universidade Federal de Lavras (UFLA), CP 3037, 37200-000, Lavras, MG, Brasil. E-mail: mribeiro@posgrad.ufla.br. Autor para correspondência.

IIDepartamento de Agricultura, UFLA, Lavras, MG, Brasil.

IIIDepartamento de Agronomia, Universidade José do Rosário Vellano (UNIFENAS), Alfenas, MG, Brasil. 
2003). As respostas da planta não dependem apenas de ausência ou presença de luz, mas também da variação em qualidade luminosa (FELIPPE, 1986). Para otimizar a captação da energia luminosa para a fotossíntese, as plantas desenvolveram uma série de fotorreceptores que regulam seu crescimento e desenvolvimento em relação à presença, quantidade, direção, duração e qualidade da radiação luminosa incidente (MORINI \& MULEO, 2003).

As lâmpadas fluorescentes, bastante comuns em salas de crescimento de laboratórios, são citadas como a principal fonte de luz utilizada em $90 \%$ dos trabalhos sobre pesquisas em cultura de tecidos. $\mathrm{O}$ custo referente à iluminação em sala de crescimento pode atingir $65 \%$ do total de gastos com energia elétrica na produção de mudas em laboratório, sendo superado apenas pelos gastos com mão-de-obra (STANDAERTDE-METSANAERE, 1991).

A alta irradiância pode afetar diretamente o desenvolvimento das plantas in vitro, apresentando efeito sobre a lâmina foliar e modificando características, tais como espessura foliar, diferenciação do mesofilo, divisão celular e desenvolvimento dos estômatos. $\mathrm{O}$ fator luz também influencia a fotossíntese, a concentração de clorofila e a estrutura dos cloroplastos em plantas cultivadas in vitro (LEE et al., 1988).

Além dos reguladores de crescimento, a luz também influencia a taxa de multiplicação e o crescimento dos explantes in vitro. Maior número de brotos por explantes de bananeira foi obtido em casa de vegetação (KODYM \& ZAPATA-ARIAS, 1998). Uma provável explicação para essa elevada taxa de multiplicação seria que a alta intensidade luminosa poderia estar reduzindo as concentrações de auxinas endógenas das gemas pela fotoxidação, provocando um desbalanceamento hormonal favorável às citocininas (RADMANN et al., 2001; SOONTOUNCHAINAKSAENG etal., 2001).

As Zantedeschias são plantas economicamente importantes, e as plantas oriundas de cultura de tecidos são uma alternativa de material para plantio, principalmente para a produção de rizomas ou flores de corte (CLEMENS \& WELSH, 1993). Contudo, existem poucas informações disponíveis sobre o modo como a qualidade da luz influencia o crescimento de Zantedeschia in vitro. Em consequência disso, o presente trabalho teve como objetivo verificar a influência de diferentes espectros de luz e de concentrações de sacarose sobre a multiplicação in vitro de copo-de-leite.

\section{MATERIAL E MÉTODOS}

O trabalho foi realizado no Laboratório de Cultura de Tecidos Vegetais, localizado no Departamento de Agricultura da Universidade Federal de Lavras, em Lavras, Minas Gerais (MG). Plantas de copo-de-leite (Zantedeschia aethiopica (L.) Spreng.) foram obtidas a partir do estabelecimento in vitro de gemas em meio contendo os sais do meio MS (MURASHIGE \& SKOOG, 1962), acrescido de $30 \mathrm{~g} \mathrm{~L}^{-1}$ de sacarose e com $\mathrm{pH}$ ajustado para 5,8. Os cultivos foram mantidos em sala de crescimento, por 60 dias, com lâmpadas brancas frias proporcionando $35 \mu \mathrm{mol}$ $\mathrm{m}^{-2} \mathrm{~s}^{-1}$, com 16 horas de fotoperíodo, a $27 \pm 1^{\circ} \mathrm{C}$.

Plantas produzidas na etapa anterior com, aproximadamente, $1,0 \mathrm{~cm}$ de comprimento foram utilizadas em meio MS. Os tratamentos foram constituídos de diferentes espectros de luz (branca, vermelha, azul e verde), fornecidos por lâmpadas fluorescentes coloridas tubulares Ecolume 05/08 T8/ $20 \mathrm{~W}$, fabricadas na China, e concentrações de sacarose $\left(0 ; 15 ; 30 ; 45\right.$ e $\left.60 \mathrm{~g} \mathrm{~L}^{-1}\right)$ em todas as combinações possíveis. $\mathrm{O}$ meio foi acrescido de $5 \mathrm{mg} \mathrm{L}^{-1}$ de BAP, sendo o $\mathrm{pH}$ ajustado para 5,8 antes da autoclavagem a $121^{\circ} \mathrm{C}$ e $1 \mathrm{~atm}$, por 20 minutos. Após a inoculação dos explantes, os tubos de ensaio foram transferidos para sala de crescimento, a $27 \pm 1^{\circ} \mathrm{C}$, irradiância de $35 \mu \mathrm{mol} \mathrm{m}{ }^{-2}$ $\mathrm{s}^{-1}$ e fotoperíodo de 16 horas. A irradiância, ao nível dos explantes, foi igual para todos os tratamentos de luz.

Após 60 dias de cultivo, foram realizadas avaliações nas seguintes variáveis: número $(\mathrm{NB})$ e comprimento de brotos (CB), número de folhas (NF) e fitomassa fresca da parte aérea (FFPA). A variável CB foi medida em centímetros e em régua milimetrada, a variável MFPA foi medida em gramas e seu peso foi observado em balança AB204 Mettler Toledo.

O delineamento experimental foi o inteiramente casualizado, em um fatorial $4 \times 5$ combinando luz (branca, vermelha, azul e verde) e concentrações de sacarose $\left(0 ; 15 ; 30 ; 45\right.$ e $\left.60 \mathrm{mg} \mathrm{L}^{-1}\right)$, com quatro repetições de três explantes cada. Os resultados foram submetidos à análise de variância, utilizando-se o software Sisvar (FERREIRA, 2000), sendo as médias produzidas sob os diferentes tipos de luz comparadas pelo teste de Scott \& Knott. Para o fator concentrações de sacarose, foi efetuada análise de regressão, a 5\% de probabilidade de erro.

\section{RESULTADOS E DISCUSSÃO}

A análise de variância mostrou interação significativa entre os fatores espectros de luz e as concentrações de sacarose apenas para número de 
folhas (NF). A sacarose foi significativa para número de folhas (NF), número de brotos (NB) e fitomassa fresca da parte aérea (FFPA). O tipo de luz foi significativo para número de folhas (NF) e número de brotos (NB).

Observou-se maior número de brotos $(2,2)$ com $45 \mathrm{~g} \mathrm{~L}^{-1}$ de sacarose (Figura 1), com o aumento da concentração diminuindo a média da variável (Tabela 1). Para Zantedeschia sp., $50 \%$ de sais do meio MS contendo $90 \mathrm{~g} \mathrm{~L}^{-1}$ de sacarose aumentaram o desenvolvimento de microrizomas (KUBO et al., 2005). Concentrações de $2 \%$ a $4 \%$ de sacarose são mais utilizadas para o crescimento e a multiplicação in vitro. Porém, altas concentrações foram eficientes para a multiplicação de Eucalyptus ficifolia. A concentração de sacarose afeta a assimilação de nutrientes e o efeito de reguladores de crescimento. Além disso, influencia a produção de metabólitos secundários, de grande importância nos processos metabólicos e na composição da parede celular.

Resultados contraditórios foram encontrados em Zantedeschia albomaculata, em que maior número de brotos $(2,0)$ ocorreu em luz branca e vermelha + azul (CHANG et al., 2003). Na multiplicação in vitro do porta-enxerto de Prunus GF 677, MORINI \& MULEO (2003) obtiveram maior número de brotos em luz branca. ERIG \& SCHUCH (2006), estudando a multiplicação in vitro de macieira, cultivares 'Galaxy' e 'Mastergala', observaram que maior número de brotos $(2,04)$ foi obtido na cultivar 'Mastergala', em presença de $4,4 \mu \mathrm{M}$ de BAP, em luz branca e amarela.

Para framboesa (Rubus idaeus L.), maior número de brotos foi obtido com as luzes verde $(3,55)$ e vermelha $(3,14)$ (ERIG \& SCHUCH, 2005). Plantas cultivadas sob luz azul podem resultar em altas taxas de brotações laterais, em razão da quebra da dominância apical causada pela degradação de auxinas nessa faixa do espectro(CHEE \& POOL, 1989; SILVA\& DEBERGH, 1997). No cultivo in vitro do porta-enxerto de macieira MM106, a luz verde proporcionou a maior taxa de proliferação de brotos. MARKS \& SIMPSON (1999), trabalhando com o cultivo de Disanthus cercidifolius e com cultivares de Rhododendron e Crataegus oxyacantha, concluíram que a luz vermelha promoveu a maior brotação. LUCA et al. (2001) verificaram que as plantas de Alternanthera brasiliana L., cultivadas sob luz verde, formaram até quatro brotos por explante, enquanto, sob luzes vermelha e branca no escuro, o número de brotos foi de dois por explante. A luz vermelha, em comparação com a luz branca, também incrementou o número de brotos axilares em culturas in vitro de Rhododendron, Potentilla e Spiraea (NORTON et al., 1988).

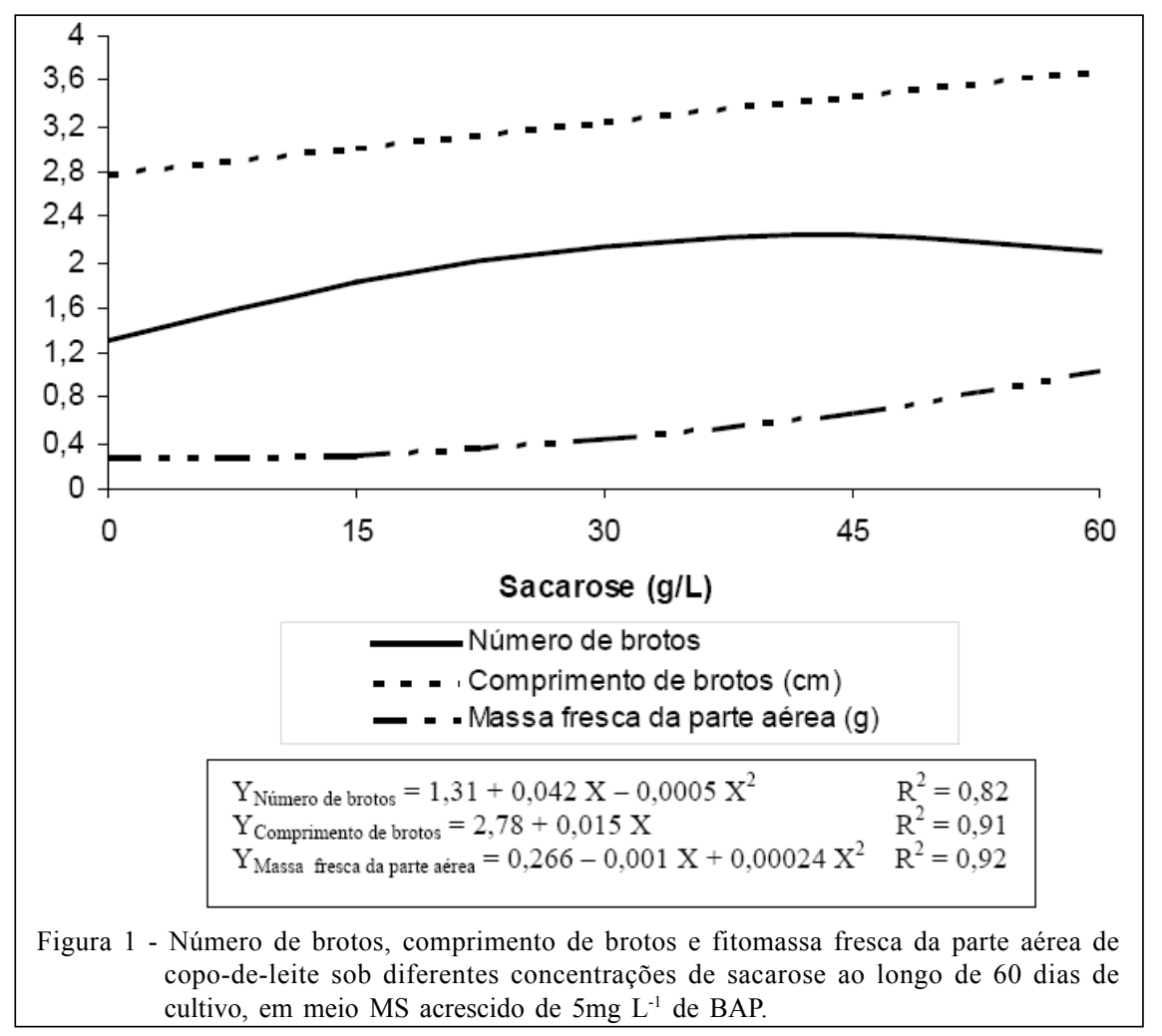

Ciência Rural, v.39, n.8, nov, 2009. 
Tabela 1 - Média do número de brotos (NB), comprimento de brotos (CB) e fitomassa fresca da parte aérea (FFPA) em função dos diferentes espectros luminosos.

\begin{tabular}{lccc}
\hline Espectros Luminosos & NB & CB (cm) & FFPA (g) \\
\hline Azul & $1,69 \mathrm{~B}$ & $2,78 \mathrm{~A}$ & $0,38 \mathrm{~A}$ \\
Verde & $1,83 \mathrm{~B}$ & $3,22 \mathrm{~A}$ & $0,40 \mathrm{~A}$ \\
Vermelha & $1,93 \mathrm{~B}$ & $3,34 \mathrm{~A}$ & $0,39 \mathrm{~A}$ \\
Branca & $2,23 \mathrm{~A}$ & $3,36 \mathrm{~A}$ & $0,41 \mathrm{~A}$ \\
CV $(\%)$ & 21,15 & 17,70 & 41,26 \\
\hline
\end{tabular}

Médias não seguidas pela mesma letra na vertical diferem entre si pelo teste Tukey, a 5\% de probabilidade de erro.

Maior comprimento de brotos $(3,7)$ foi observado em alta concentração de sacarose, $60 \mathrm{mg} \mathrm{L}^{-1}$ (Figura 1). Discordando desses resultados, LUCA et al. (2001) demonstraram que explantes de Alternanthera brasiliana desenvolvidos sob luz azul e verde apresentaram crescimento por alongamento dos brotos $(4,0)$ mais acentuado. CHANG et al. (2003) observaram maior comprimento de brotos sob luz vermelha $(9,76 \mathrm{~cm})$ e luz azul $(9,34 \mathrm{~cm})$ em Zantedeschia albomaculata. ERIG \& SCHUCH (2006) observaram que, na cultivar 'Mastergala', a luz amarela proporcionou o melhor resultado para o comprimento do broto mais desenvolvido $(0,88 \mathrm{~cm})$ em macieira. TURCHETTO et al. (2005) obtiveram, em Tagetes, o crescimento dos brotos $(90,9 \mathrm{~mm})$ sob luz azul em meio $\mathrm{MS}$ e $50 \mathrm{~g} \mathrm{~L}^{-1}$ de sacarose.
A interação significativa para número de folhas foi observada em luz branca $(3,8)$, seguida de luz azul $(2,9)$, associadas a 15 e $60 \mathrm{~g} \mathrm{~L}^{-1}$ de sacarose, respectivamente (Figura 2). A luz branca é a mais utilizada em cultura de tecidos e seus efeitos sobre a morfogênese já são conhecidos. A luz azul é importante na formação da clorofila, no desenvolvimento do cloroplasto, na abertura do estômato e na fotomorfogênese (AKOYUNOGLOU \& ANNI, 1984). Resultados semelhantes ocorreram em Alternanthera brasiliana, que apresentou maior número de folhas por explante em presença de luz azul, seguida pelas folhas submetidas às luzes brancas e verdes (LUCA et al., 2001).

Maior teor de sacarose no meio de cultivo corresponde à maior concentração de carboidratos no tecido foliar. Em consequência, as folhas têm capacidade de permanecer mais tempo na planta (CALVETE et al., 2002). O aumento na concentração de sacarose do meio de $3 \%$ para $5 \%$ promoveu aumento de massa em folhas de rosa micropropagadas sob condições heterotrotóficas ou mixotróficas (CAPELLADES et al.,1991).

Folhas irradiadas com luz branca absorvem mais os comprimentos de ondas azul e vermelha e grande parte do verde. Talvez esse fato justifique os resultados deste trabalho, apesar de as luzes vermelha e verde não terem proporcionado os melhores resultados (SALISBURY \& ROSS, 1992).

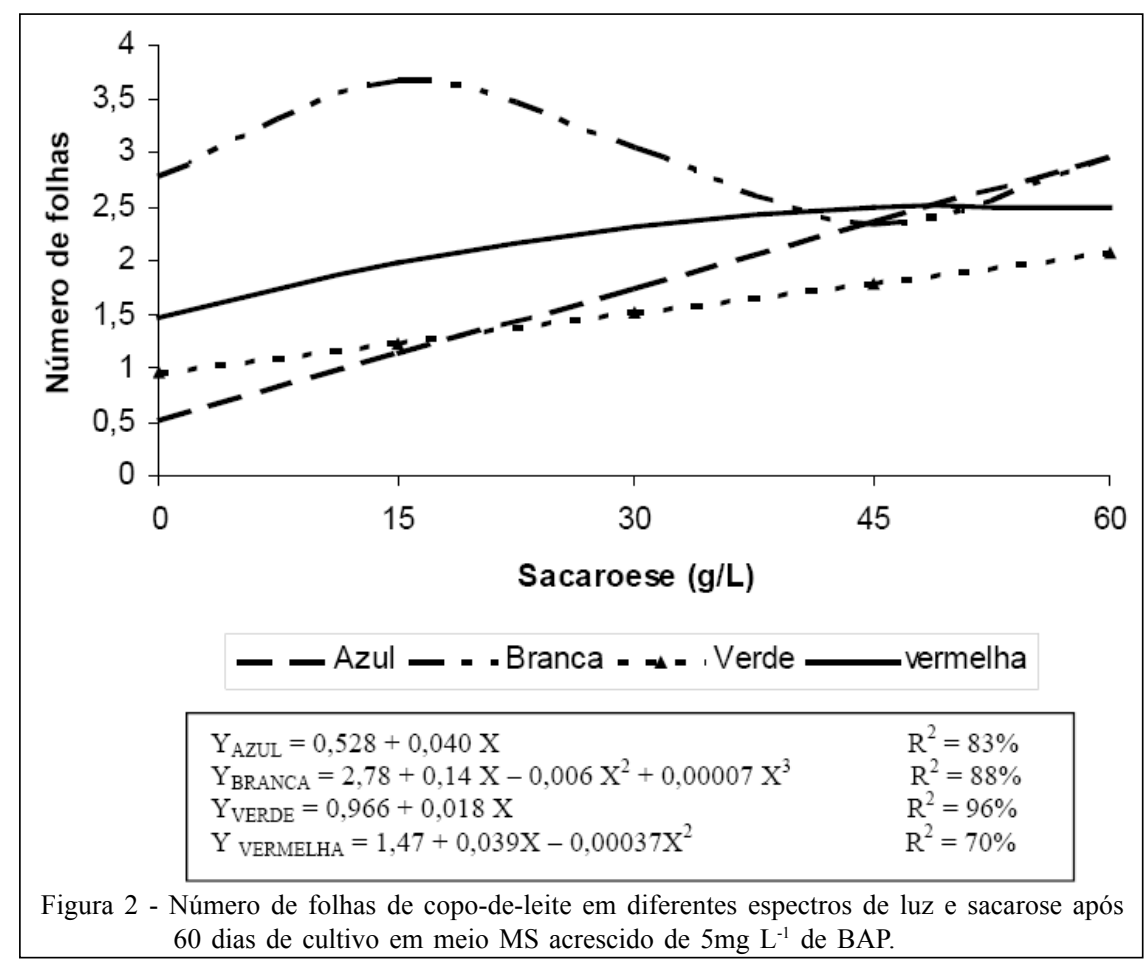

Ciência Rural, v.39, n.8, nov, 2009. 
Geralmente, luz azul e vermelha são fortemente atenuadas na parte superior da folha, enquanto luz verde e vermelho-distante são transmitidas mais profundamente dentro da folha (CUI et al., 1991).

Maior fitomassa fresca da parte aérea $(1,07)$ foi observada em presença de $60 \mathrm{~g} \mathrm{~L}^{-1}$ de sacarose (Figura 1). Foram obtidos resultados contrastantes em Zantedeschia albomaculata, pois, para essa espécie, maior fitomassa fresca da parte aérea $(0,40)$ foi observada em luz vermelha (CHANG et al., 2003). Explantes desenvolvidos em meio com $60 \mathrm{~g} \mathrm{~L}^{-1} \mathrm{de}$ sacarose podem ter o desenvolvimento da parte aérea inibido. APPELGREN (1991) mostrou aumento significativo na elongação do caule de explantes de Pelargonium cultivado in vitro, e AKSENOVA et al. (1994) afirmaram que plântulas de batata cultivadas in vitro produziram caules mais longos e maiores taxas de brotos e raízes sob luz vermelha.

\section{CONCLUSÕES}

O tipo de luz não influencia a multiplicação in vitro de copo-de-leite. Além disso, o maior número de brotos $(2,0)$ é obtido em $45 \mathrm{~g} \mathrm{~L}^{-1}$ de sacarose. Observase maior número de folhas em luz branca $(3,8)$ e azul $(2,9)$, em 15 e $60 \mathrm{~g} \mathrm{~L}^{-1}$ de sacarose, respectivamente. Maior comprimento dos brotos $(3,7 \mathrm{~cm})$ é observado em $60 \mathrm{~g} \mathrm{~L}^{-1}$ de sacarose, e maior fitomassa fresca da parte aérea $(1,07 \mathrm{~g})$ é observada em $60 \mathrm{~g} \mathrm{~L}^{-1}$ de sacarose.

\section{REFERÊNCIAS}

AKOYUNOGLOU, G.; ANNI, H. Blue light effect on chloroplast development in higher plants. In: SENGER, H. (Ed.). Blue light effects in biological systems. Berlin: Springer-Verlag, 1984. p.397-406.

AKSENOVA, N.P. et al. Morphogenesis of potato plants in vitro. I. Effect of light quality and hormones. Journal of Plant Growth Regulation, New York, v.13, n.3, p.143-146, 1994. Disponível em: < http://www.springerlink.com/content/j17g807188145j53/>. Acesso em: 20 nov. 2006. doi: 10.1007/BF00196378.

APPELGREN, M. Effects of light quality on stem elongation of Pelargonium in vitro. Scientia Horticulturae, Amsterdam, v.45, n.3/4, p.345-351, 1991. Disponível em: <http:// www.sciencedirect.com/science?>. Acesso em: 12 jun. 2006. doi:10.1016/0304-4238(91)90081-9.

CALVETE, E.O. et al. Concentração de sacarose no enraizamento in vitro de morangueiro. Horticultura Brasileira, Brasília, v.20, n.2, p.186-191, 2002. Disponível em: <http://www.scielo.br/ scielo.php?pid=S0102-05362002000200014\&script $=$ sci_arttext $>$. Acesso em: 12 out. 2006. doi: $10.1590 / \mathrm{S} 0102$ 05362002000200014 .

CAPELLADES, M. et al. Effects of sucrose on starch acumulation and rate of photosyntesis in Rosa cultured in vitro. Plant Cell
Tissue and Organ Culture, Dordrecht, v.25, n.1, p.21-26, 1991. Disponível em: <http://www.springerlink.com/content/ x823wu54r3v85242/>. Acesso em: 01 nov. 2006. doi: 10.1007/ BF00033908.

CHANG, H.S. et al. Micropropagation of Calla lily (Zantedeschia albomaculata) via in vitro shoot proliferation. In Vitro Cellular \& Developmental Biology-Plant, Wallingford, v.39, n.2, p.129-134, 2003. Disponível em: <http:// www.springerlink.com/content/j324274107177w47/ fulltext.pdf $>$. Acesso em: 04 jul. 2006. doi: 10.1079/ IVP2002362.

CHEE, R.; POOL, R.M. Morphogenetic responses to propate trimming, spectral irradiance, and photoperiod of gravepine shoots recultured in vitro. Journal of the American Society for Horticultural Science, Alexandria, v.114, n.2, p.350354, 1989 .

CLEMENS, J.; WELSH, T.E. An overview of the New Zealand calla industry, research directions and year-round tuber production. Acta Horticulture, Amsterdam, v.337, p.161166, 1993. Disponível em: <http://www.actahort.org/members/ showpdf?booknrarnr=337_22>. Acesso em: 16 jan. 2006.

CUI, M.et al. Chlorophyll and light gradients in sun and shade leaves of Spinacia oleracea. Plant, Cell \& Environment, Oxford, v.14, n.5, p.493-500, 1991. Disponível em: <http:// www3.interscience.wiley.com/journal/119351639/issue > Acesso em: 03 out. 2006. doi: 10.1111/j.1365-3040.1991.tb01519.x.

ERIG, A.C.; SCHUCH, M.W. Tipo de luz na multiplicação in vitro de framboeseira (Rubus idaeus L.) 'Batum'. Revista Brasileira de Fruticultura, Jaboticabal, v.27, n.3, p.488-490, 2005. Disponível em: $<$ http://www.scielo.br/scielo.php?script=sci_arttext\&pid=S0100$29452005000300035 \& \mathrm{nrm}=$ iso\&lng=es>. Acesso em: 04 jul. 2006. doi: 10.1590/S0100-29452005000300035.

ERIG, A.C.; SCHUCH, M.W. Ação da 6-Benzilaminopurina e da qualidade da luz na multiplicação in vitro de macieira (Malus domestica Borkh.) cvs. Galaxy e Mastergala. Revista Brasileira de Agrociência, Pelotas, v.12, n.2, p.151-155, 2006. Disponível em: <http://www.ufpel.tche.br/faem/ agrociencia/v12n2/artigo05.pdf $>$. Acesso em: 06 jul. 2006.

FELIPPE, G.M. Fotomorfogênese. In: FERRI, M.G. (Coord.). Fisiologia vegetal 2. 2.ed. São Paulo: EPU, 1986. p.231280 .

FERREIRA, D.F. Análises estatísticas por meio do Sisvar para Windows versão 4.0. In: REUNIÃO ANUAL DA REGIÃO BRASILEIRA DA SOCIEDADE INTERNACIONAL DE BIOMETRIA, 45., 2000, São Carlos. Anais... São Carlos: UFSCar, 2000. p.255-258.

KODYM, A.; ZAPATA-ARIAS, F.J. Natural light as an alternative lighe source for the in vitro culture of banana (Musa acuminata cv. 'Grande Naine'). Plant Cell Tissue and Organ Culture, Dordrecht, v.55, n.2, p.141-145, 1998. Disponível em: <http:// www.springerlink.com/content/13990j3474114124>. Acesso em: 06 out. 2006. doi: 10.1023/A:1006119114107.

KUBO, T. et al. Factors affecting the formation and growth of microtubers in Zantedeschia plantlets. Japanese Society for Horticultural Science, Kyoto, v.74, n.1, p.47-50, 2005. 
Disponível em: $<$ http://www.jstage.jst.go.jp/article/jjshs/74/1/47/ _pdf>. Acesso em: 12 out. 2006.

LEE, N. et al. Quantum flux density effects on the anatomy and surface morphology of in vitro-and in vivo developed sweetgum leaves. Journal of American Society for Horticultural Science, Alexandria, v.113, n.1, p.167-171, 1988.

LUCA, R.L. et al. Ação de diferentes faixas do espectro luminoso na otimização da produção de Alternanthera brasiliana $\mathbf{L}$., uma planta medicinal. In: ENCUENTRO LATINOAMERICANO DE BIOTECNOLOGÍA VEGETAL, 4., 2001, Goiânia. Anais... Goiânia: Redbio, 2001. 6p.

MARKS, T.R.; SIMPSON, S.E. Effect of irradiance on shoot development in vitro. Plant Growth Regulation, Farnham Royal, v.28, n.2, p.133-142, 1999. Disponível em: <http:// www.springerlink.com/content/h3g2t6170484h758/ fulltext.pdf $>$. Acesso em: 12 set. 2006. doi: 10.1023/ A: 1006276724956.

MORINI, S.; MULEO, R. Effects of light quality on micropropagation of woody species. In: JAIN, S.M.; ISHII, K. Micropropagation of woody trees and fruits. Dordrecht: Kluwer Academic, 2003. p.3-35

MURASHIGE, T.; SKOOG, F.A. A revised medium for rapid growth and bioassays with tobacco tissue cultures. Physiologia Plantarum, Copenhagen, v.15, n.3, p.473-497, 1962.

NORTON, C.R. et al. Light quality and light pipe in the micropropagation of woody ornamental plants. Acta Horticulturae, Amsterdam, n.226, p.413-416, 1988. Disponível em: <http:// www.actahort.org/members/showpdf?booknrarnr $=226 \quad 51>$. Acesso em 12 out. 2006 .
RADMANN, E.B. et al. Influência da densidade de fluxo luminoso na qualidade de plantas micropropagadas de Gypsophila paniculata L. Revista Brasileira de Agrociência, Pelotas, v.7, n.3, p.171-175, 2001. Disponível em < http:// www.ufpel.tche.br/faem/agrociencia/v7n3/artigo02.pdf $>$. Acesso em: 06 out. 2006

SALISBURY, F.B.; ROSS, C.W. Relación fotosíntesis transpiración. In: Fisiología vegetal. México: Grupo Editorial Iberoamérica, 1992. p.71-100.

SILVA, M.H.; DEBERGH, P C. The effect of light quality on the morphogenesis of in vitro cultures of Azorina vidalii (Wats.) Feer. Plant Cell Tissue and Organ Culture, Amsterdam, v.51, n.3, p.187-193, 1997. Disponível em: <http:// www.springerlink.com/content/w728324k5284236g/>. Acesso em: 12 agosto 2006. doi: 10.1023/A:1005988621036.

SOONTOUNCHAINAKSAENG, P. et al. In vitro studies on the effect of light intensity on plant growth of Phaius tankervilliae (Banks ex L' Herit) Bl. and Vanda coerulea Giff. Science Asia, Shanghai, v.27, p.233-237, 2001. Disponível em: <http:/ /www.scienceasia.org/2001.27.n4/content.html $>$. Acesso em: 14 set. 2006. doi: 10.2306/scienceasia1513-1874.2001.27.233.

STANDAERT-DE-METSANAERE, R.E. Economic considerations. In: DEBERGH, P.C.; ZIMMERMAN, R.H. (Ed.). Micropropagation - technology and application. Dordrecht: Kluwer Academic, 1991. p.131-140.

TURCHETTO, A.C. et al. Influência da qualidade da luz na multiplicação in vitro de Tagetes sp. In: CONGRESSO DE INICIAÇ̃̃O CIENTÍfICA, 14., 2005, Pelotas. Anais... Pelotas: Faculdade de Agronomia Eliseu Maciel, 2005. 1 CD. 